LAWRENCE LIVERMORE N A T IO N A L LABORATORY
Whole Genome Amplification of DNA from Residual Cells Left By Incidental Contact

K.J. Sorensen, K.W. Turteltaub, G. Vrankovich, J. Williams, A.T. Christian

November 24, 2003

Analytical Biochemistry 
This document was prepared as an account of work sponsored by an agency of the United States Government. Neither the United States Government nor the University of California nor any of their employees, makes any warranty, express or implied, or assumes any legal liability or responsibility for the accuracy, completeness, or usefulness of any information, apparatus, product, or process disclosed, or represents that its use would not infringe privately owned rights. Reference herein to any specific commercial product, process, or service by trade name, trademark, manufacturer, or otherwise, does not necessarily constitute or imply its endorsement, recommendation, or favoring by the United States Government or the University of California. The views and opinions of authors expressed herein do not necessarily state or reflect those of the United States Government or the University of California, and shall not be used for advertising or product endorsement purposes. 


\section{Whole Genome Amplification of DNA from Residual Cells Left By Incidental Contact}

Sorensen, K.J. ${ }^{1}$, Turteltaub, K. ${ }^{2}$, Vrankovich, G., Williams, J., Christian, A., T. ${ }^{2} *$

1. Biology and Biotechnology Research Program, Lawrence Livermore National Laboratory. P.O. Box 808, L-446. Livermore, CA, 94551

2. Biology and Biotechnology Research Program, Lawrence Livermore National Laboratory. P.O. Box 808, L-452. Livermore, CA, 94551

Keywords:

Fingerprints

DNA isolation

PCR analysis

*Please address correspondence to:

Allen Christian

Biology and Biotechnology Research Program

Lawrence Livermore National Laboratory

PO Box 808, L-452

Livermore, CA. 94551

phone: (925) 424-5909

fax: (925) 424-3130

e-mail: christian4@llnl.gov 


\begin{abstract}
$\underline{\text { Abstract }}$
Typically, the number of genetic analyses performed on a sample of DNA has been limited by the amount of starting material. For example, the small quantity of DNA obtained from the cells within a fingerprint meant that only a five to ten reactions could be performed off a single sample. We demonstrate a process wherein total genomic DNA is amplified before forensic typing analysis. The process requires as few as 8 cells and produces sufficient material for up to 20,000 subsequent PCR reactions. The technique is particularly useful to enhance current methods of latent print analysis and has been shown to be compatible with common forensic print visualization and removal techniques including dye staining and powders.
\end{abstract}




\section{$\underline{\text { Introduction }}$}

Latent fingerprint analysis is a powerful tool for forensic investigators.

Visualization techniques have been developed which allow prints to be found on nearly any surface and databases are continually being expanded to give investigators more and more power to identify individuals. Recent advances have been made in molecular biology that are now enabling investigators to perform analyses on the DNA in cells left behind in latent prints. Latent fingerprints that are smudged or incomplete are not useful for traditional analysis. The ability to use the cells left behind in these prints for genetic analysis would greatly improve an investigator's ability to obtain useful information from a print (van Oorschot and Jones 1997).

Several recent papers have investigated the usefulness of cells contained in latent fingerprints for genetic typing analyses. Van Oorschot (van Oorschot and Jones 1997) demonstrated that sufficient cells could be removed from several different surfaces to allow typing analysis. Schulz et al (Schulz and Reichert 2002) published successful genetic analysis on fingerprint samples that had been processed and archived. Zamir et al were able to analyze the DNA contained in cells from adhesive tape used in processing for fingerprints. Van Renterghem et al (van Renterghem, Leonard et al. 2000) even published successful use of genetic print analysis from latent prints in two separate forensic cases.

In spite of the potential, there are still many problems associated with the use of cells contained in latent prints for forensic analysis. Prints that are successfully lifted can be used for only a limited number of analyses. Schulz et. al. (Schulz and Reichert 2002) published that only five analyses could be performed from one amplified sample. Most prints yield a limited quantity of DNA; van Oorshot obtained 1-50 ng of DNA from each print (van Oorschot and Jones 1997), and Schulz obtained <0.75 ng DNA from archived prints (Schulz and Reichert 2002). Because of these problems the success rate is generally low using traditional amplification and typing procedures. Schulz et al (2002) published 14 out of 48 prints were successfully amplified and typed, and only 9 out of 48 were successful when archived prints were used. 
In 2002, Hawkins et al. published a paper discussing recent advances in whole genome amplification, (Hawkins, Detter et al. 2002) including a new method of strand displacement amplification using $\Phi 29$ polymerase, which is known for its high processivity and strand displacement capabilities. Studies using this enzyme have shown a very low error rate of 1 in $10^{6}-10^{7}$ (Esteban et al, 1993), compared to 3 in 10,000 for Taq DNA polymerase (Lundberg et al, 1991). Whole genome amplification using this enzyme can be obtained in a fashion similar to rolling circle amplification by combining the polymerase with random hexamer primers. The technique has been shown to provide complete, non-biased amplification of the starting material, producing as much as $20-30 \mu \mathrm{g}$ of DNA from as few as 10 cells.

We demonstrate the use of strand displacement whole genome amplification to amplify samples before forensic analysis. Using this method, DNA removed from a surface or print is amplified before analysis, providing sufficient material for the DNA from a single sample to be used for thousands of DNA-based assays, including PCR. Consistent, successful amplification has been achieved in our lab with as few as eight whole cells (recovered by microdissection to determine precise numbers) or as little as $10 \mathrm{fg}$ of isolated DNA. Following amplification, the DNA can be used for a virtually unlimited number of PCR or STR analyses. 


\section{$\underline{\text { Materials and Methods }}$}

Determining Sensitivity. The sensitivity of the amplification was tested in parallel from two different starting sources. In the first, 1, 2, 4, 6, 8 or $10 \log$ phase MOLT-4 cells were placed by micromanipulation into microfuge tubes. In the second, log phase MOLT- 4 cells were diluted in PBS to yield the following concentrations: $10^{6}$ cells $/ \mathrm{ml}, 10^{5}$ cells $/ \mathrm{ml}, 10^{4}$ cells $/ \mathrm{ml}$ and $10^{3}$ cells $/ \mathrm{ml}$. One $\mu 1$ from each tube was used as starting material, such that reactions were performed containing 1, 10, 100, and 1000 cells. In both cases, reactions believed to contain only one cell were performed in triplicate. Amplification was performed using the Repli $G$ kit available from Molecular Staging, Inc, or the Templiphi kit available from Amersham. Postamplification samples were run on a $2 \%$ agarose gel in TBE and tested by inter-alu PCR (add reference to TC-65) to determine the quality of amplification.

Serial Dilution Experiment. To determine the quantity of amplified product needed for subsequent typing analysis, serial dilutions of 1:10, 1:100 and 1:1000 in water were made of samples amplified both by the Repli-G kits. $1 \mu 1$ of each of the diluted materials was used as template material for an alu-PCR reaction (APO primers were used, as published in Watkins, et al 2001). PCR was also performed on the undiluted material. Samples were run on a $2 \%$ agarose gel to determine the success of the reaction.

Comparison to non-amplified material. Buccal swabs were taken from 10 individuals using Epicentre Collection Swabs. DNA was extracted following the manufacturer's procedure outlined in the Repli-G kit. Extracted DNA was either amplified using the Repli-G procedure before STR typing analysis or used directly for typing analysis. Typing was done using the GammaSTR multiplex kit available from Promega. Products were viewed using $2 \%$ agarose gels. 


\section{Results}

Determining Sensitivity. Results of this experiment are shown in Figure 1 and 2. Figure 1a shows a $2 \%$ agarose gel of microdissected human MOLT-4 cells that have undergone whole genome amplification. It can be seen that samples containing greater than eight cells showed successful amplification. Figure $1 \mathrm{~b}$ shows the same samples following inter-alu PCR, confirming that the samples indeed contained human DNA. In cases where the quantity of starting material was estimated following serial dilution, figure $2 \mathrm{a}$, it can be seen that the tubes containing greater than 10 cells were also successfully whole genome amplified. Figure $2 \mathrm{~b}$ confirms the presence of human DNA by inter-alu PCR.

Samples estimated by dilution to contain 10 cells appear to have produced different amounts of product from one another, and less product overall than those collected by microdissection. This is not surprising given the method of collection, which is inaccurate at such low numbers. Following inter-alu PCR, these differences become less apparent.

In early experiments, both the Repli-G kit (Molecular Staging, Inc) and the Templiphi kit (Amersham) were used, as both contained the $\Phi 29$ polymerase and random hexamers. While both kits performed satisfactorily, we found the Repli-G consistently produced larger quantities of product DNA. For this reason, we began to use the Repli-G kit exclusively in later experiments.

Serial Dilution Experiment. Results of this experiment are shown in Figure 3. It can be seen that successful PCR was performed on amplified samples that had been diluted as much as 1:1000. As expected, the quantity of product was dependent upon the initial dilution. At 1:1000 the product band appears to be very faint, but is still a definite band.

Using this experiment it can be estimated that the $50 \mu \mathrm{L}$ of product produced by whole genome can be diluted 1000 times, producing $50,000 \mu \mathrm{L}$ of usable product for genetic typing analysis. As an example, this is enough to run 20,000 STR typing analyses if one uses the GammaSTR kit, as we did. 
Comparison to non-amplified material. STR analysis was successful on 8 out of 10 buccal swabs that had been pre-amplified by Repli-G. The analysis was successful on only 3 out of 10 buccal swabs that had not been pre-amplified. 


\section{$\underline{\text { Discussion }}$}

The method outlined in this paper has the potential to allow virtually unlimited DNA-based analyses to be performed on a single sample. This offers a significant improvement over current technology. Schulz et al published that they could type only five different STR loci from a single sample. Conservative estimations in our lab suggest that from a single amplified sample containing $50 \mu 1,1: 1000$ dilutions can be performed producing 50,000 $\mu 1$, thereby allowing up to 20,000 subsequent reactions from one fingerprint.

Great care must be taken when collecting samples, to avoid contamination. Because the assay is so sensitive, even trace amounts of DNA will become a significant problem. Contamination can come from several sources, including the technicians handling and collecting the samples. Samples can also become contaminated before collection. Studies by van Oorschot and Jones (van Oorschot and Jones 1997) demonstrated that DNA could be transferred between individuals by a handshake and objects handled by many individuals showed profiles from several people. We are currently investigating methods to deal with this, both avoiding it if possible and determining if it has occurred.

This method could allow many previously unusable samples to be analyzed. In cases where only smudged or partial prints can be located traditional fingerprint analysis would be impossible. Using this method, adequate material can be obtained to perform genetic analysis. Work in our lab performing strand displacement whole genome amplification on bacteria, shows consistent results using as little as a single cell. Suggesting that the assay may become even more sensitive following optimization. We anticipate this method will proove useful even in cases where no prints are visible, but skin contact is suspected. 


\section{$\underline{\text { Acknowledgements }}$}

This work was performed under the auspices of the U. S. Department of Energy by the University of California, Lawrence Livermore National Laboratory under Contract No. W-7405-Eng-48 with support from the Central Intelligence Agency.

\section{$\underline{\text { References }}$}

Hawkins, T. L., J. C. Detter, et al. (2002). "Whole genome amplification--applications and advances." Curr Opin Biotechnol 13(1): 65-7.

Schulz, M. M. and W. Reichert (2002). "Archived or directly swabbed latent fingerprints as a DNA source for STR typing." Forensic Sci Int 127(1-2): 12830.

van Oorschot, R. A. and M. K. Jones (1997). "DNA fingerprints from fingerprints." Nature 387(6635): 767.

van Renterghem, P., D. Leonard, et al. (2000). "Use of latent fingerprints as a source of DNA for genetic identification." Progress in Forensic Genetics 8: 501-503.

Watkins, W.S., Ricker, C.E., Bamshad, M.J., Carrol, M.L., Nguyen, S.V., Batzer, M.A., Harpending, H.C., Rogers, A.R., and Jorde, L.B. (2001). "Patterns of ancestral human diversity: an analysis of alu-insertion and restriction-site polymorphisms." Am J Hum Genet 68:738-752.

Zamir, A., Springer, E., Glattstein, B. (2000). "Fingerprints and DNA: STR typing of DNA extracted from adhesive tape after processing for fingerprints." $\underline{J}$ Forensic Sci 45 (3):687-688. 


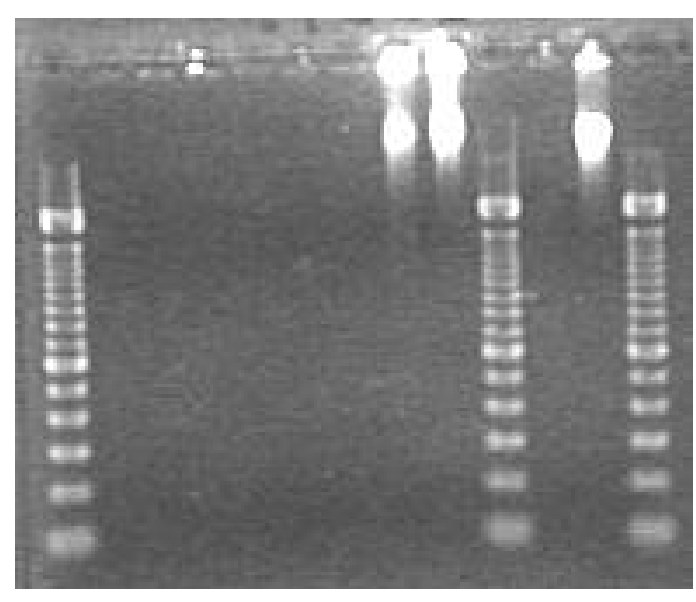

Figure 1a

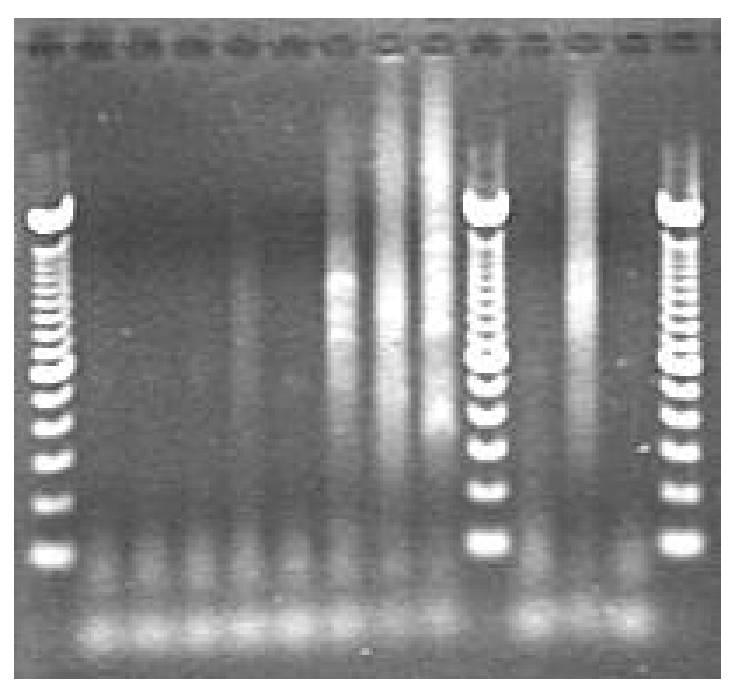

Figure $1 b$

Figure 1a shows $2 \%$ agarose gels of varying numbers of human MOLT-4 cells that had been microdissected and then whole genome amplified. Lanes 1, 10 and 13 contain 100 bp DNA ladders. Lanes 2-4 were made from a single cell each, lane 5 was made from 2 cells, lane 6 was made from 4 cells, lane 7 was made from 6 cells, lane 8 from 8 cells and lane 9 from 10 cells. Lanes 11 and 12 contain positive and negative controls, respectively. Figure $1 \mathrm{~b}$, lanes 1-10 shows the same samples following inter-alu PCR, loaded in the same order. Lanes 11, 12 and 113 show negative, positive and negative controls.

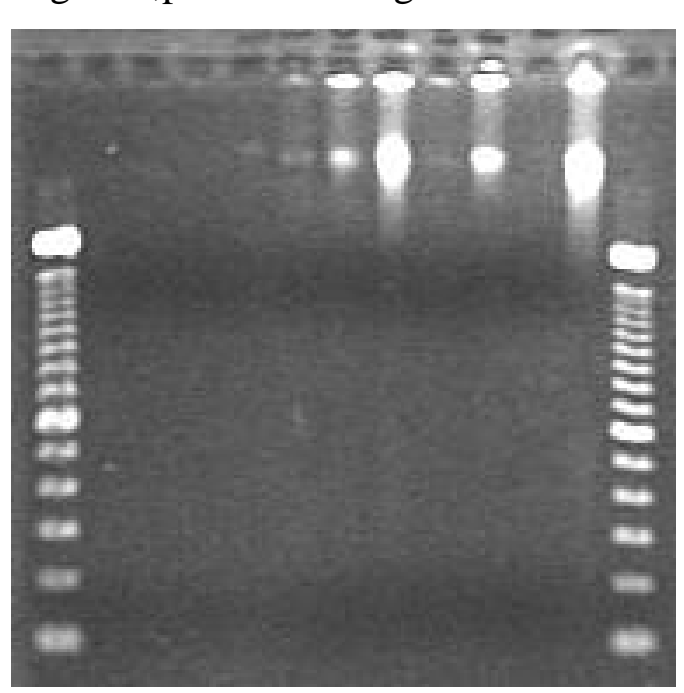

Figure 2a

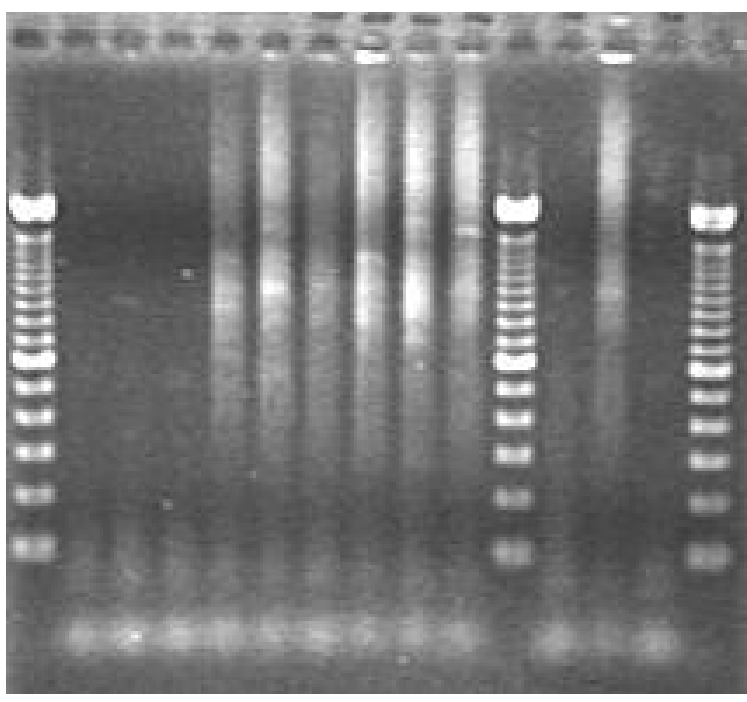

Figure $2 b$

Figure 2a shows a $2 \%$ agarose gel of serially diluted human MOLT-4 cells following whole genome amplification. Dilutions were prepared which were estimated to contain 1 cell as starting material in lanes $2-4,10$ cells as starting material in lanes 56,100 cells as starting material in lanes 7-8 and 1000 cells as starting material in lanes 9-10. Lanes 11 and 12 contain negative and positive controls, respectively. Figure $2 b$ contains the same samples following inter-alu PCR, loaded in the same order. In this case, however, a ladder separates the test_samples from the controls, negative, positive and negative in lanes 12-14. All ladders used were 100 bp DNA ladders. 


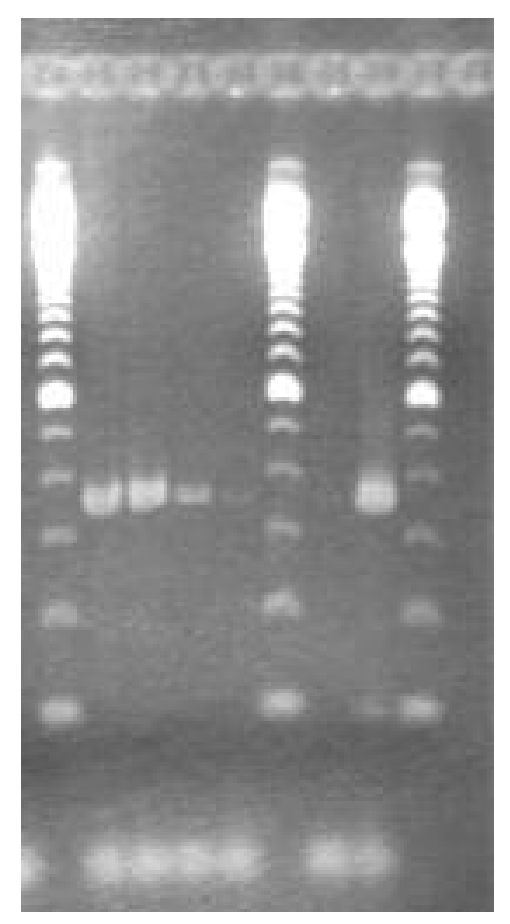

\section{Figure 3.}

$2 \%$ agarose gel showing PCR products from serially diluted, whole genome amplified templates. In lanes 1,6 and 9 are 100 base pair DNA ladders. In lanes 2 through 5 are alu-PCR products. APO primers were used (Watkins, Ricker et al. 2001) on amplified templates that had been diluted 1:10, 1:100 and 1:1000 (lanes 3-5) or not diluted (lane 2). Lanes 7 and 8 show negative and positive controls, respectively. Note that product can clearly be seen at 1:100 dilution and faintly seen at 1:1000 dilution. 